\title{
Geostatistical Analysis of Soil Properties to Support Spatial Sampling in a Paddy Growing Alfisol
}

\author{
V.G.D. Nayanaka, W.A.U. Vitharana ${ }^{1 *}$ and R.B. Mapa \\ Postgraduate Institute of Agriculture \\ University of Peradeniya \\ Sri Lanka
}

\begin{abstract}
The information on the spatial and temporal variability of soil properties is vital to improve soil management and to increase the crop productivity. This study was conducted to explore the spatial variability of agronomically important soil properties of a paddy growing tract in Pulasthigama in Polonnaruwa district of Sri Lanka. The study area consisted of 18 ha and a total of 43 soil samples were collected within the plough depth (0$20 \mathrm{~cm}$ ). The variability of soil clay content, organic matter, available $P, p H$, electrical conductivity (EC), exchangeable calcium and available zinc were investigated by means of classical and geostatistical analysis techniques. The coefficient of variation of properties ranged from $5 \%(\mathrm{pH})$ to $140 \%$ (Zn content). According to the calculated variograms, the available $P$, clay content and organic matter exhibited a highly spatially structured variability whereas a medium structured variability was observed for soil $\mathrm{pH}$. Pure nugget effects were observed for both available $\mathrm{Zn}$ and exchangeable Ca contents indicating a dominance of a random variation. The observed spatial dependencies of soil properties can be used to support spatial sampling for detailed soil mapping and thereby it is suggested that management practices such as fertilizer application, irrigation and tillage operations can be fine tuned at a within fields scale to maximize rice crop production while minimizing the detrimental effects on environment.
\end{abstract}

Key words: Rice, Semi-variogram, Site-specific soil management, Spatial variability.

\section{INTRODUCTION}

Rice is the staple food of 20.45 million Sri Lankans and is the livelihood of more than 1.8 million farmers. More than $30 \%$ of the total labour force is directly or indirectly involved in the rice farming. The annual per capita consumption of rice is approximately $122 \mathrm{~kg} / \mathrm{year}$ (Central Bank Report, 2009). It has been projected that with the present population growth rate of $1.1 \%$, Sri Lanka may require about 3.83 million tons of paddy by the year 2020 (Abeysiriwardene and Sandanayake, 2000). However, the available land resource for the cultivation of paddy is limited. Therefore, in order to cater to this demand, efforts should be made to explore the full potential of existing paddy growing lands. Soil being a major natural resource in the rice growing ecosystems, should be at optimum quality with its physical, chemical and biological properties in combination with other management practices to enhance the productivity and hence to cater to the future demand. Traditional soil management does not account for the natural field scale soil variability and considers

1* To whom correspondences should be addressed to: uvithara@pdn.ac.lk

Department of Soil Science, Faculty of Agriculture, University of Peradeniya, Peradeniya, Sri Lanka 
agricultural fields in a particular area as more homogenous units (Vitharana, 2008). Sitespecific soil management is one of the promising approaches to increase the productivity of existing arable lands while minimizing the over utilization of natural resources (Mulla and Schepers, 1997). Site-specific soil management implies the concept of managing soils on the basis of spatial variation of soil properties which the crop growth. Thus, management practices such as tillage operations, fertilizer and application of agro-chemicals are performed on a site-specific basis (Larson and Robert, 1991). The implementation of sitespecific soil management practices requires the characterization of spatial variability of soil properties. This creates requirements for estimating and mapping the spatial variability of soil properties at a detailed scale. Classical statistical techniques are not appropriate enough to characterize the spatial variability of soil (Goovaerts, 1997). In this context, geostatistics offers an alternative approach where spatial correlation (or autocorrelation) of variables can be quantified through variogram analysis (Webster and Oliver, 2001; Neilson, 2008) and subsequent accurate mapping.

The objectives of this study, therefore, were to explore the spatial variability of some agronomically important soil properties in paddy growing soils and geostatistically analyze the spatial dependencies to support spatial sampling for preparing detailed soil mapping required in site-specific soil management.

\section{MATERIALS AND METHODS}

\section{Description of the study area}

This study was carried out in 2008/2009 at the beginning of the Maha season in a paddy growing tract in Pulasthigama $\left(8^{\circ} 04^{\prime} 40.89^{\prime \prime} \mathrm{N}, 81^{\circ} 04^{\prime} 38.43^{\prime \prime} \mathrm{E}\right)$ in Polonnaruwa district of Sri Lanka. The study area consisted of 18 ha where most of the area consisted of flat to undulating terrain belonging to the DL1c Agro ecological Region (Punyawardane et al., 2003). Irrigation water is supplied to the area by six field channels connected to a distribution channel. Major soils found are Reddish Brown Earths (Rhodustalfs) and Low Humic Gley (Tropaqualfs) which is the hydromorphic association of the Reddish Brown Earths. Mutugala series is the dominant soil series found in this area (Mapa et al., 2009).

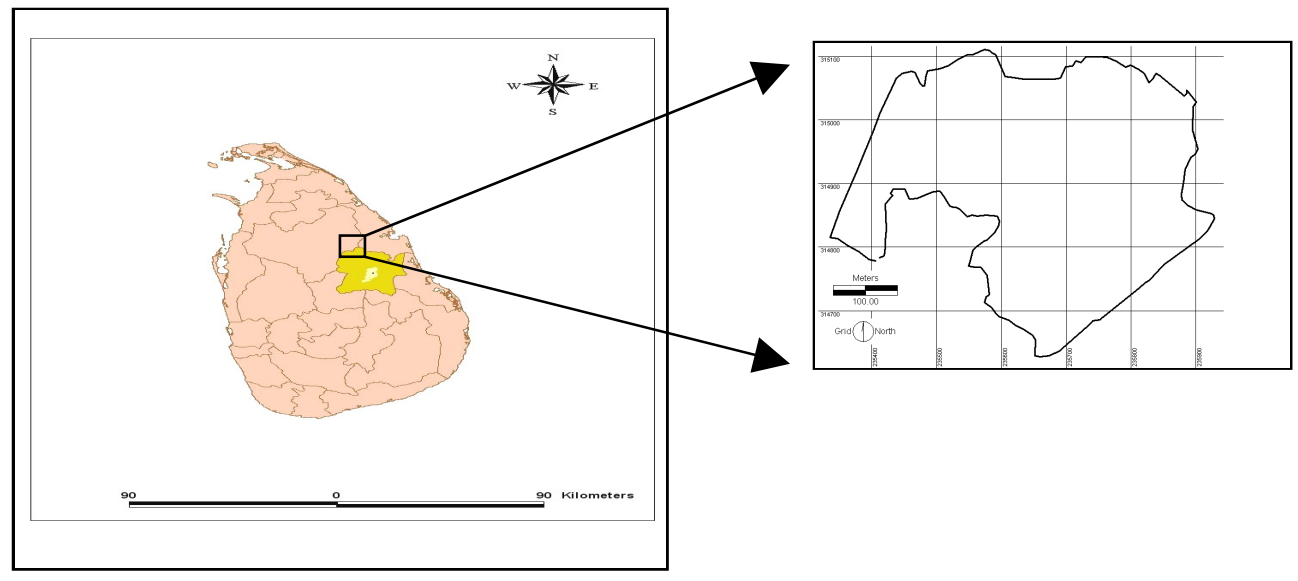

Fig. 1. Location of the study area in Polonnaruwa district of Sri Lanka 


\section{Soil sampling and laboratory analysis}

Soil sampling was done at the beginning of the Maha season. Samples were collected from 43 locations covering the entire area. Distribution of sampling sites was adjusted as far as possible to match the distribution pattern of paddy fields of each farmer. Geographical coordinates of all sampling locations were recorded using Global Positioning System (GPS). In each location, soils were sampled from a $20 \mathrm{~cm}$ depth using a Gouge augur and sub soil samples were then obtained around the geo-reference point to obtain a composite sample. Soil samples were air dried, crushed and passed through $2 \mathrm{~mm}$ sieve prior to analysis.

The soil properties measured were texture, organic matter, $\mathrm{pH}$, available phosphorous, Electrical Conductivity (EC), exchangeable $\mathrm{Ca}$ and available $\mathrm{Zn}$. Soil texture was determined by Pipette method (Gee and Or, 2002). Dichromate oxidation method was used to assess the soil organic matter content as described by Walkley and Black (Nelson \& Sommers, 1996). Soil $\mathrm{pH}$ was measured using glass electrode $\mathrm{pH}$ meter in distilled water using a soil to water ratio of 1:2.5. Electrical conductivity meter was used to measure the EC of 1:5 soil water suspensions. Available phosphorous was determined by Olsen method (Kuo, 1996). Ammonium acetate extraction at $\mathrm{pH} 7.0$ was used to determine the exchangeable calcium. Available $\mathrm{Zn}$ was determined by $0.05 \mathrm{M} \mathrm{HCl}$ extraction method (especially for paddy soils).

\section{Statistical analysis}

Exploratory data analysis was performed by SPSS (version 13) software. The data distributions were analyzed by classical statistics (mean maximum, minimum, standard deviation, skewness, kurtosis and coefficient of variation). The skewness and kurtosis coefficients are often used to describe the shape and flatness of data distribution respectively. Histograms and Box-plots for each soil property were inspected for the possible outliers which affect the descriptive statistics and the characterization of spatial variation. Plotting the values of observations on a distribution map was used to verify whether extreme values which are linked to the measurement errors or to several mixed populations within the study area. Further, the spatial variability of the selected properties was interpreted by means of distribution maps. Experimental semi-variograms were calculated for each soil property using equation (1)

$$
\gamma(\mathbf{h})=\frac{1}{2 \mathrm{~N}(\mathbf{h})} \sum_{a=1}^{\mathrm{N}(\mathbf{h})}\left[\mathrm{z}\left(\mathbf{x}_{a}\right)-\mathrm{z}\left(\mathbf{x}_{a}+\mathbf{h}\right)\right]^{2}
$$

Where $\gamma(h)$ is the semivariance for the lag distance $h . N(h)$ is the number of sample pairs separated by the lag distance $h, z\left(\mathbf{x}_{\alpha}\right)$ is the measured value at $\alpha^{\text {th }}$ sample location and $\mathrm{z}\left(\mathbf{x}_{\alpha}+\mathrm{h}\right)$ is the measured value at point $\alpha+\mathrm{h}^{\text {th }}$ sample location. Theoretical models (Spherical, Exponential or Gaussian) were fitted to experimental semivariograms. Model selection for semivariograms was done on the basis of goodness of model fit criterion available with Variowin software (Pannatier, 1997). The parameters of the variogram model namely, nugget semivariance, range and sill semivariance were determined to characterize the spatial dependencies (structures) of different soil properties. In order to explore the spatial structure of a particular variable at different directions of the field, the variograms can be calculated for major directions of a study area (Goovaerts, 1997). This requires a large number of 
samples. Therefore, in this study directional aspect of the spatial dependence was not considered and the omnidirectional variograms were calculated.

\section{RESULTS AND DISCUSSION}

Results of the exploratory and geostatistical analysis of the observed soil properties are presented below.

\section{Descriptive statistics and distribution maps}

The coefficient of variation, which is the ratio of the standard deviation to mean expressed as a percentage is a useful measure of overall variability. Coefficient of variation ranged from $5 \%(\mathrm{pH})$ to $140 \%(\mathrm{Zn})$. According to the classification of Hillel (1980), $\mathrm{pH}$ showed low variability $(<10 \%)$ and other variables except $\mathrm{Zn}$ showed medium variability $(10 \%-100 \%)$ whereas available $\mathrm{Zn}$ had a high variability $(>100 \%)$. The range of $\mathrm{CV}$ for the area suggested different degrees of heterogeneity among the properties studied.

The skewness and kurtosis coefficients are zero for a normally distributed random variable. If the data distributions are largely deviated from a normal distribution, data transformations are often performed in order to reduce the influence of extreme values on spatial analysis (Webster and Oliver, 2001). However, considering the observed skewness coefficient values data were not transformed.

Table 1 shows the summary statistics of the measured soil properties of the samples. Mean clay content was 7.46 which indicated relatively low clay content in the top soil of the area. According to the distribution pattern (Fig. 2a) clay content has increased along the catenary sequence of the area resulting in higher values in the low lying area.

Table 1. Summary statistics for soil test values obtained from 43 samples

\begin{tabular}{lccccccc}
\hline Soil property & Mean & Min & Max & SD & CV\% & SC & KC \\
& & & & & & & \\
\hline Clay (\%) & 7.46 & 4.00 & 10 & 1.54 & 21 & -0.30 & -0.40 \\
OM (\%) & 1.77 & 1.01 & 2.82 & 0.45 & 26 & 0.65 & -0.39 \\
Av. P $(\mathrm{mg} / \mathrm{kg})$ & 16.39 & 9.67 & 42.85 & 7.71 & 47 & 2.07 & 3.99 \\
pH $(1: 2.5)$ & 6.28 & 5.76 & 7.15 & 0.33 & 5 & 0.67 & -0.16 \\
EC $(1: 5)(\mathrm{dS} / \mathrm{m})$ & 0.06 & 0.03 & 0.16 & 0.03 & 48 & 1.96 & 3.69 \\
Ex. Ca $(\mathrm{mg} / \mathrm{kg})$ & 456.83 & 103.30 & 987.50 & 259.13 & 58 & 0.46 & -1.04 \\
Av. $\mathrm{Zn}(\mathrm{mg} / \mathrm{kg})$ & 0.96 & 0.02 & 5.71 & 1.34 & 140 & 2.02 & 4.08 \\
\hline
\end{tabular}

(SD: standard deviation, CV: coefficient of variation, SC: skewness coefficient and $\mathrm{KC}$ : kurtosis coefficient). 

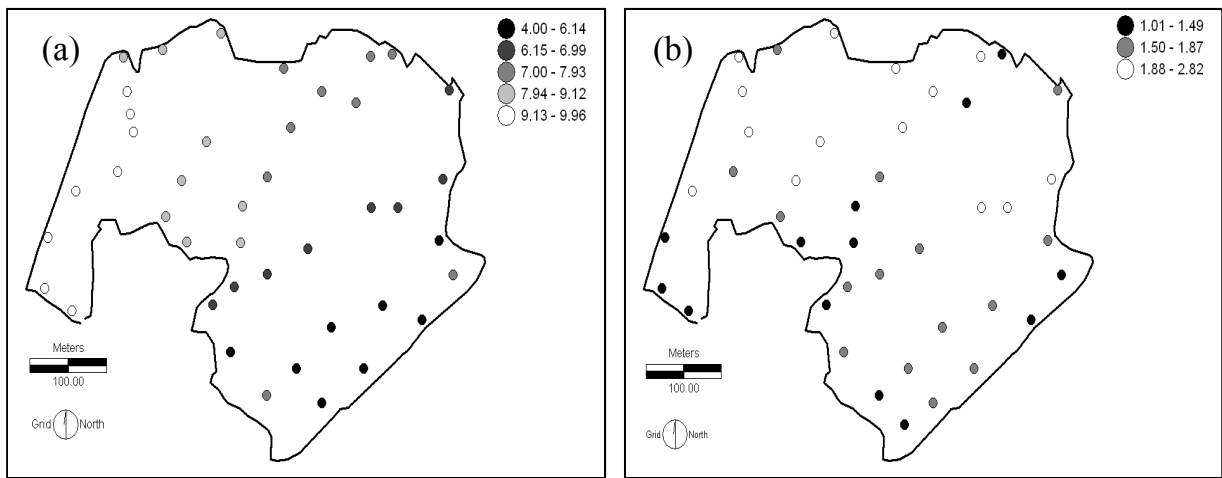

Fig. 2. Distribution of (a) the top soil clay content (\%) and (b) organic matter content $(\%)$.

Organic matter content varied from 1.01 to $2.82 \%$ and the distribution was positively skewed due to few high values observed in the western part of the area. Soil organic matter is one of the key parameters determining the quality of a soil. Since it governs the other soil physical, chemical and biological properties, it is known to be a vital quality parameter to sustain the rice ecosystem. Large part of the area had organic matter content of 1 to $2 \%$ indicating a depletion of organic matter in these soils. Panabokke (1996) reported that the organic matter content of rice soils in Polonnaruwa area ranges from 0.86 to $2.8 \%$. Low organic matter content reported may be due to the intensive cultivation of rice without or less addition of organic materials to the soils. Distribution of available phosphorous in the top soil is shown in Fig. 3a. Average phosphorous content was $16 \mathrm{mg} / \mathrm{kg}$ whereas more than half of the area had phosphorous content of less than $10 \mathrm{mg} / \mathrm{kg}$ (Fig. 3a).
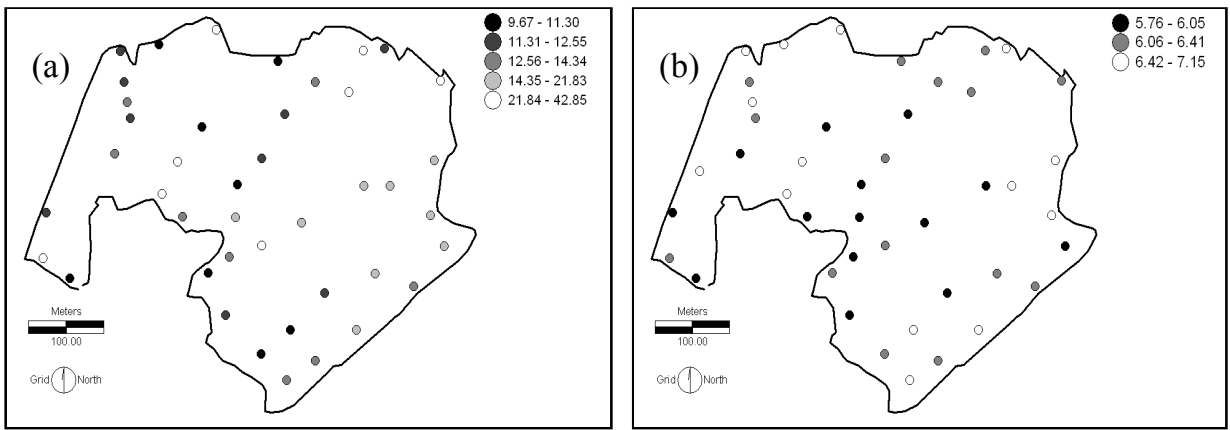

Fig. 3. Distribution of (a) soil available phosphorous (mg/kg) and (b) soil pH

According Doberman and Fairhurt (2000) the critical level of available phosphorous for rice is $10 \mathrm{mg} / \mathrm{kg}$. Kenderagama (2003) also reported that large part of the dry zone soils had available phosphorous less than $10 \mathrm{mg} / \mathrm{kg}$ and significant yield reduction was observed due to insufficient phosphorous content in these soils. Soil $\mathrm{pH}$ is an important chemical property governing the availability of nutrients in the soil nutrient pool. The variation of top soil $\mathrm{pH}$ in the study area is shown in Fig. 3b. Soil pH ranged from 5.76 to 7.15 and had a coefficient of variation of $5 \%$ showing a low relative variability.

Electrical Conductivity (EC) is one of the major parameters assessing the salinity status of a soil. Salinity is a problem situation in soils accumulation of excess soluble salts due to high 
evapotranspiration, poor drainage and poor quality irrigation water. Distribution pattern of electrical conductivity values is shown in Fig. 4a. According to the distribution pattern, major part of the area showed low electrical conductivity values $(<0.05 \mathrm{dS} / \mathrm{m})$ indicating no salinity hazard. High skewness coefficient is attributed to some higher electrical conductivity values in isolated places.
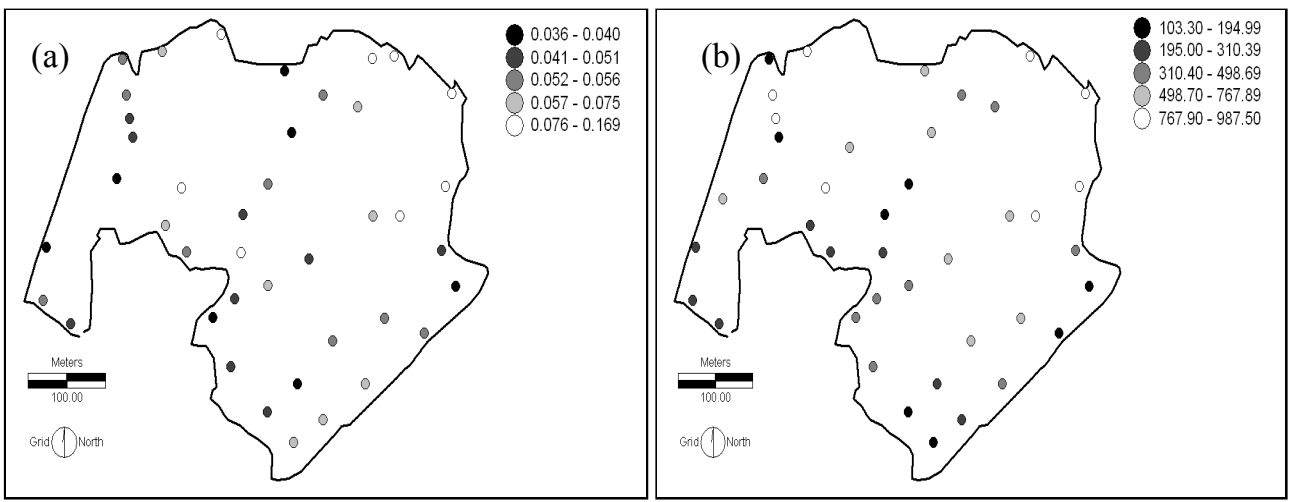

Fig. 4. Distribution of (a) soil electrical conductivity (dS/m) and (b) soil exchangeable calcium (mg/kg).

Distribution pattern of electrical conductivity values showed a similarity with that of the exchangeable calcium in the area. High exchangeable calcium values were observed in the valleys of the undulating terrain in the eastern part of the study area.

Zinc is the most limiting micro-nutrient in the dry zone soils of Sri Lanka (Bandara, 2007). According to the distribution pattern (Fig. 5), more than $80 \%$ of the area had zinc levels of less than $1 \mathrm{mg} / \mathrm{kg}$ which is the critical level in soil for optimum rice plant nutrition (Dobermann and Fairhurt, 2000).

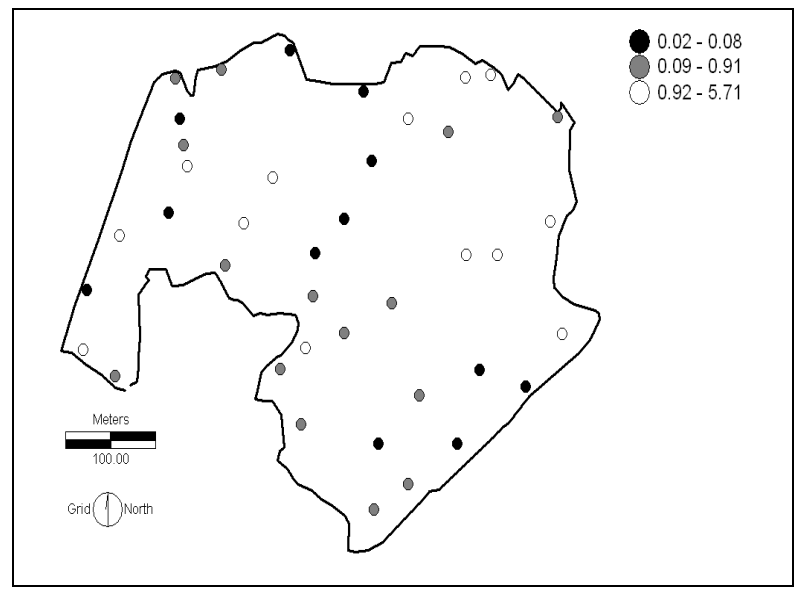

Fig. 5. Distribution of the available Zinc ( $\mathrm{mg} / \mathrm{kg})$ 


\section{Geostatistical analysis}

The experimental variograms for top soil properties and the models fitted are shown in Fig. 6 and model parameters are summarized in Table 2.
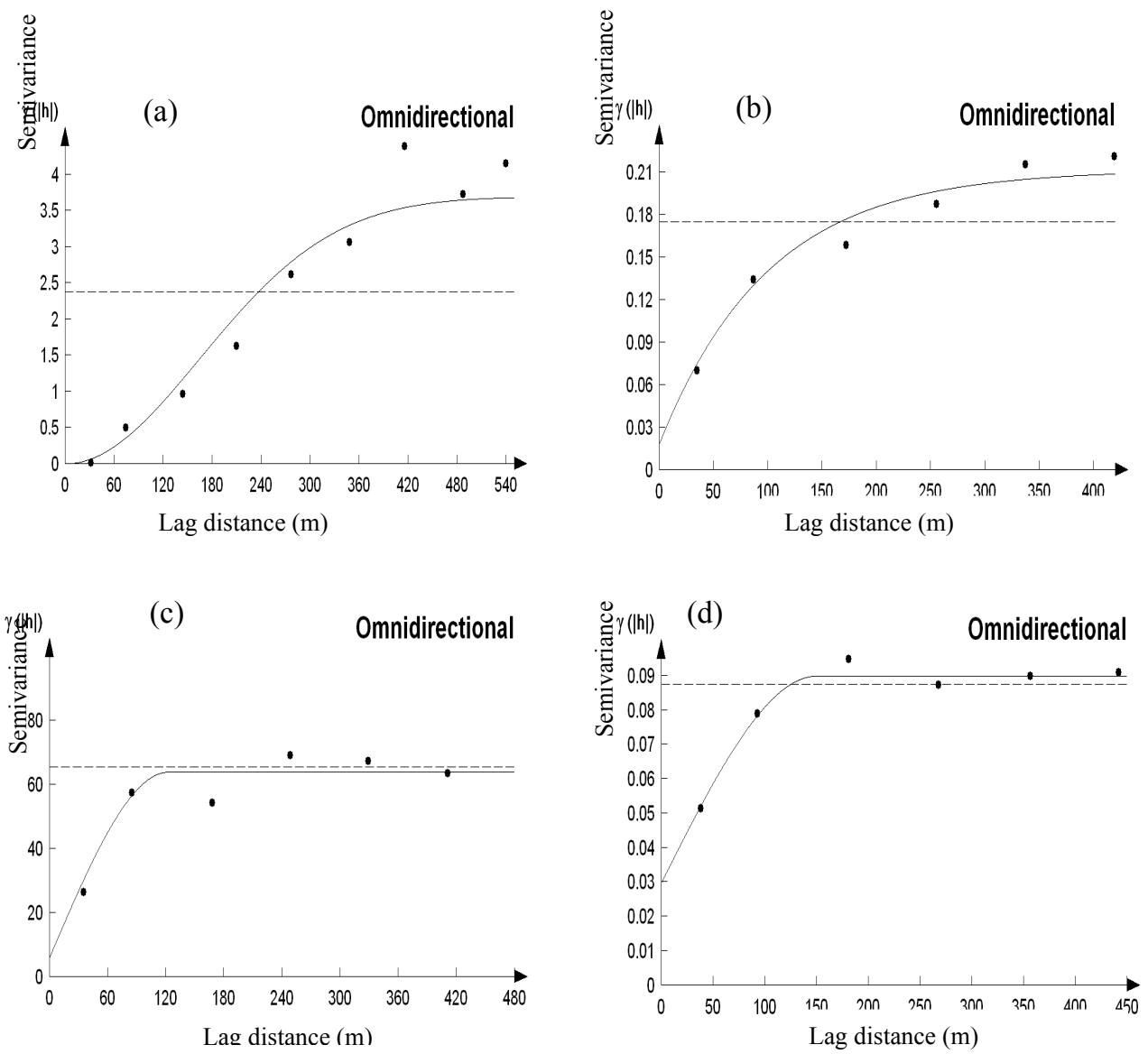

Fig. 6. Omni-directional variograms (dots) and fitted models (curves) for (a) soil clay, (b) organic matter, (c) available phosphorous and (d) $\mathrm{pH}$.

The variogram shows the relationship between the lag distance (h: distance between the measurements of a particular property) and the corresponding semivariance (see equation 1). The variogram describes the spatial correlation (correlation with the distance) of a spatially varying property. In a highly spatially correlated variable, the semivariance increases from low values near to the origin to the larger values as $\mathrm{h}$ increases. This indicates higher spatial correlation at the small lag distances and a reduction of the spatial correlation as the distance between a variable increases. The dissimilarity increases until it eventually reaches a maximum value of $\gamma(\mathrm{h})$ at which the variogram flattens. This is called sill variance, which theoretically approximates the total variance of the variable. The lag $h$ at which the 
variogram reaches the sill variance represents the range of spatial correlation. It is considered that the observations within the range are spatially correlated, whereas those greater than the range are considered as spatially independent (Goovaerts, 1997). By definition, semivariance at lag zero is itself zero. But, often for soil data, the variogram intercepts the ordinate at a positive semivariance value which is called as the nugget variance. This represents random variation or any measurement errors. Therefore, the ratio of nugget effect to sill or relative nugget effect $(\mathrm{RNE}=$ nugget/sill) can be calculated as percentage to indicate the proportion of spatially unstructured variation in relation to the total variation.

Table 2. Model parameters of the variograms of soil properties

\begin{tabular}{lllllll}
\hline Property & Direction & \multirow{2}{*}{ Modle } & \multicolumn{2}{c}{ Variogram parameters } & \multirow{2}{*}{ RNE\% } \\
\cline { 3 - 5 } & & & Nugget & Sill & Range(m) & \\
\hline Clay & Omni & Gaussian & 0.00 & 3.70 & 403.6 & 0.00 \\
OM & Omni & Exponential & 0.018 & 0.194 & 300.31 & 9.28 \\
Available P & Omni & Spherical & 5.94 & 58.08 & 122.68 & 1.23 \\
pH & Omni & Spherical & 0.0297 & 0.0603 & 150.57 & 48.33 \\
EC & Omni & Exponential & 0.00 & 0.0012 & 299.43 & 0.00 \\
\hline
\end{tabular}

RNE- Relative nugget effect.

The range of spatial dependence varied from $400 \mathrm{~m}$ for clay to $122 \mathrm{~m}$ for available phosphorous. Clay content showed a high spatial correlation to a greater distance among the soil properties studied. Gaussian model was found as the best fit for clay. This initial flat behavior of the model represents a very strong degree of homogeneity over short distances (Gooverts, 1997). It revealed that the spatial variation of clay content is not very significant over the initial short lag distances and after it has increased towards the low lying area as a result of land preparation practices such as puddling. Puddling disturbs soil structure and releases finer clay particles which could be washed off and deposited in low lying areas of the catenary landscape. The nugget effect of clay is zero (Table 2). Thus a RNE value of zero indicated a strong spatial correlation of clay content of this area. The range of $400 \mathrm{~m}$ indicated that, for spatial sampling of this property, sampling interval can be maintained within $400 \mathrm{~m}$. Organic carbon was spatially related to a distance of $300 \mathrm{~m}$. Relative Nugget Effect (RNE) which indicates the proportion of spatially unstructured variation in relation to the total variation is $9.28 \%$. According to Cambardella (1994), this is a strongly structured spatial dependence $(<25 \%)$. According to the variogram, for spatial characterization of soil organic carbon in this area, samples can be taken within a sampling interval of $300 \mathrm{~m}$.

Available phosphorous showed the lowest range indicating spatial correlation within a smaller distance among the studied soil properties. This indicated that samples should be taken at comparatively shorter distances (within $122 \mathrm{~m}$ ). Relative Nugget Effect of available phosphorous was less than the $25 \%$ showing a highly spatial dependence (Cambardella, 1994).

Soil $\mathrm{pH}$ was spatially correlated to distance of $150 \mathrm{~m}$, however, showed a small nugget variance. Relative Nugget effect for the $\mathrm{pH}$ was $48.33 \%$ indicating a moderately structured variability. The experimental variograms of exchangeable calcium and available zinc showed a pure nugget effect, thus variogram could not be fitted to these experimental variograms (Fig. 7a and b). According to Webster and Oliver (2001) pure nugget effect 
indicates a dominance of random variation of a property. Therefore, every observation of these two variables is spatially independent from the others.
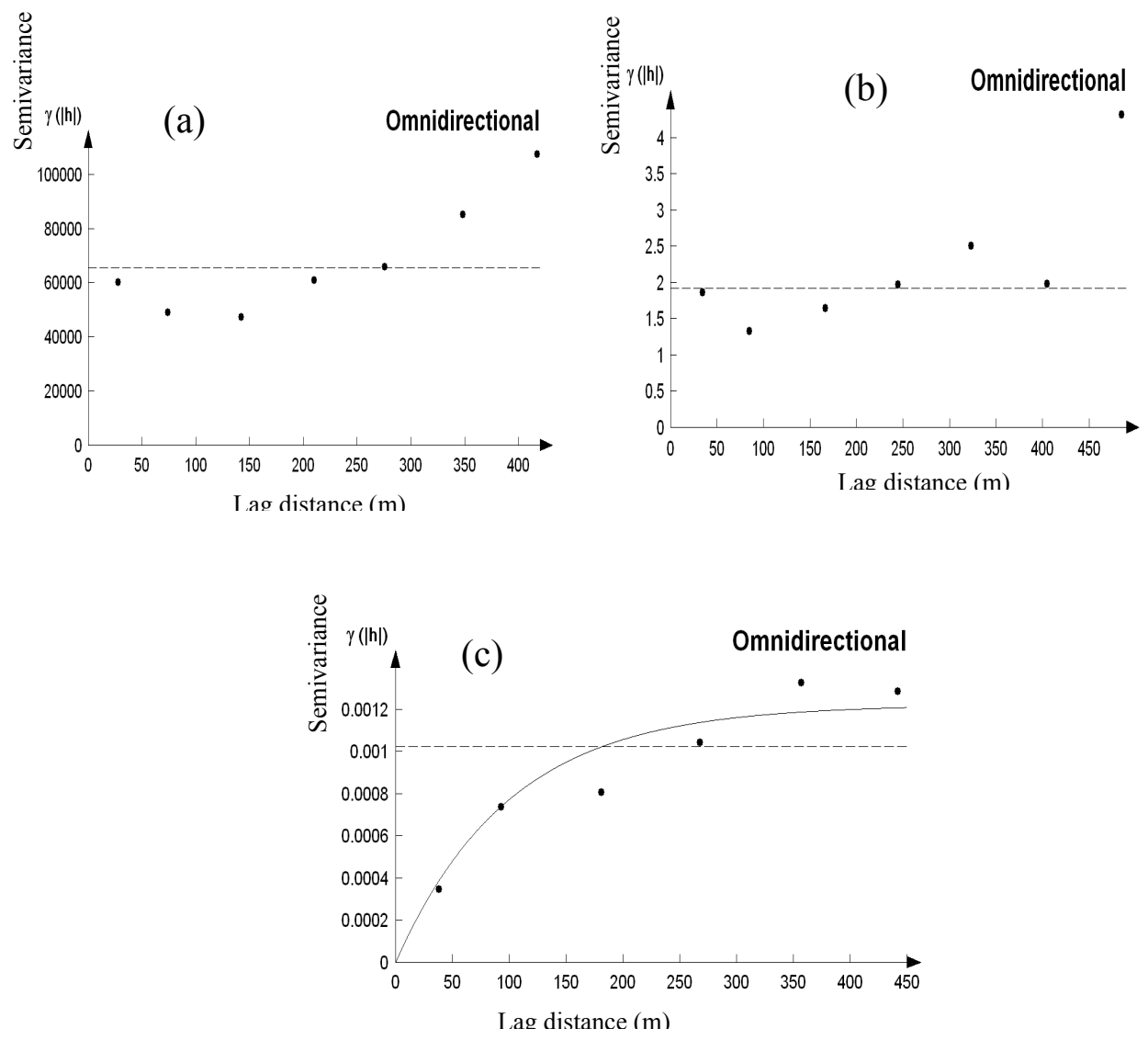

Fig. 7. Omni directional experimental variograms (dots) for (a) calcium, (b) zinc and (c) electrical conductivity with the fitted model (curve).

Since soil exchangeable calcium and available zinc did not show a spatial structure, conventional statistics parameters such as mean, standard deviation and coefficient of variation can be used to characterize the population. Mean calcium content was $456 \mathrm{mg} / \mathrm{kg}$ in the area. In spite of the inherent supply from soil, calcium is supplied mainly through irrigation water. This can lead to a random distribution of calcium in the soil. Coefficient of variation of calcium and zinc was 58 and 140, respectively and showing a medium and high relative variability respectively. The electrical conductivity showed a strong spatial dependence (Table 2) within a distance of $300 \mathrm{~m}$. This suggested that electrical conductivity (EC) values were influenced by the neighboring values of EC over comparatively greater distances. 


\section{CONCLUSIONS}

All the variables studied, except exchangeable calcium and available zinc, showed spatial dependence of the variation at different scales. This observed spatial dependency can be used to support spatial sampling for detailed soil mapping in site specific soil management. For this, the optimal sampling spacing identified in this study can be used and accurate liner interpolation technique such as kriging can be used for detailed mapping of the properties.

\section{ACKNOWLEDGEMENTS}

The authors would like to acknowledge Mr. D.N. Sirisena and Miss. W.M.U.K. Rathnayake, Rice Research and Development Institute, Batalagoda, Ibbagamuwa for the assistance given in conducting soil analysis.

\section{REFERENCES}

Abesiriwardena, D.S. and Sandanayake, S. (2000). Future rice research as directed by trends in cultivated extent and yield of rice during the recent past. Annals of the Sri Lanka Department of Agriculture. 2, 371-381.

Bandara, W.M.J. (2007). Role of Micronutrients in Balanced Nutrient Application for Rice in Dry and Intermediate zones of Sri Lanka. Soil Science Society of Sri Lanka. 19, 35-48.

Cambardella, C.A., Moorman, J.M., Navak, T.B., Parkin, D.L., Karlen, R.F., Turco and Konopka, A.E. (1994). Field Scale Variability of Soil Properties in Central Lowa Soils. J. Soil Sci. Soc. of Am. 58, 1501 - 1511.

Central Bank of Sri Lanka (2009). Annual Paddy sector statistics. Department of Censes and Statistics, Colombo, Sri Lanka.

Dobermann, A. and Fairhurst, T. (2000). Nutrient disorders and nutrient management in rice. International Rice Research Institute, Philippines, 60-89.

Gee, W.G and Or, D. (2002). Particle size analysis. pp. 151-184. In: Jacob, H. Dane, Clarke Topp G. and Warren A. Dick, (Ed.). Methods of Soil Analysis, Part 4: Physical Methods. Soil Science Society of America, Inc. Madison, WI.

Goovaerts, P. (1997). Geostatistics for Natural Resource Evaluation, Oxford University Press, New York, NY.

Hillel, D. (1980). Application of Soil Physics, Academic Press, New York, NY. pp. 380

Kendaragama, K.M.A., Seniviratne Banda, K.M. and Bandara, P.T. (2003). Influence of Rice Crop Phosphorous Availability in Relation to Phosphorous Fertilizer Application. Annuals of Sri Lanka Department of Agriculture. 5, 129-141. 
Kuo, S. (1996). Phosphorous extraction with a buffered alkaline solution. pp. 895-897. In: Sparks, D.L. and Bigham, J.M. (Ed). Method of Soil Analysis, Part 3: Chemical Methods. Soil Science Society of America, Inc. Madsion, WI.

Larson, W.E. and P.C. Robert. (1991). Farming by soil, pp. 103-112. In: Lal, R. and Prerce, J. (Ed). Soil Management for Sustainability, Soil and Water Conservation Society, Ankeny, IA.

Mapa, R.B., Somasiri, S. and Dassanayake, A.R. (2009). Soils of the Dry Zone of Sri Lanka. Morphology, Characterization and Classification. Special Publicaion No. 7. Soil Science Society of Sri Lanka. Survodaya Vishva Lekha, Colombo, Sri Lanka. pp. 249

Mulla, D.J. and Schepers, A.R. (1997). Key Processes and Properties for Site Specific Soil and Crop Management. pp. 1-18. In: Pierec, F.J. and Sadler, E.J. (Ed.). The State of Site Specific Management for Agriculture. ASA, CSSA and SSSA, Madison, WI.

Neilson, D.R. (2008). Geostatistical Methods Applied to Soil Science, In: Methods of Soil Analysis, Part 4: Physical methods. U.S.A: Soil Science Society of America.

Nelson, D.W. and Sommer L. E. (1996). Total Organic Carbon and Organic Matter, pp. 361404 In: Sparks, D.L. (Ed). Method of Soil Analysis, Part 3, Chemical Methods: American Society of Agronomy, Madison, WI.

Panabokke, C.R. (1996). Soils and Agro Ecological Environments of Sri Lanka, Natural Resources, Energy and Science Authority of Sri Lanka.

Pannatier, Y. (1997). VARIOWIN: Software for Spatial Data Analysis in 2D. Springer, NY.

Punyawardane, B.V.R., Bandara, T.M.J., Munasinghe, M.A.K., Banda, N.J., and Pushpakumara, S.M.V. (2003). Agro-ecological Regions of Sri Lanka. Natural Resource Management Center, Department of Agriculture, Peradeinya, Sri Lanka.

Vitharana, W.A.U. (2008). Spatial Inventory Techniques in Support of Site Specific Soil Management. Ph.D. Thesis, University of Ghent, Belgium.

Webster, R. and Oliver, M.A. (2001). Statistical Methods in Soil Science and Resource Survey. Oxford University Press, New York, NY. 